\title{
Prenatal maternal and cord blood vitamin D concentrations and negative affectivity in infancy
}

\author{
Sara Sammallahti ${ }^{1,2}$ - Elisa Holmlund-Suila ${ }^{3,4} \cdot$ Runyu Zou $^{1}$ - Saara Valkama ${ }^{3,4}$. Jenni Rosendahl ${ }^{3,4}$. \\ Maria Enlund-Cerullo ${ }^{3,4,5} \cdot$ Helena Hauta-alus ${ }^{3,4,6,7} \cdot$ Marius Lahti-Pulkkinen $^{8} \cdot$ Hanan El Marroun ${ }^{1,9}$. \\ Henning Tiemeier ${ }^{1,2} \cdot$ Outi Mäkitie $^{3,4,5} \cdot$ Sture Andersson $^{3} \cdot$ Katri Räikkönen $^{8} \cdot$ Kati Heinonen $^{8,10}$
}

Received: 14 June 2021 / Accepted: 6 October 2021 / Published online: 18 October 2021

(c) The Author(s) 2021

\begin{abstract}
Higher maternal vitamin D concentration during pregnancy is associated with better child mental health. Negative affectivity, an early-emerging temperamental trait, indicates an increased risk of psychopathology. We investigated if maternal early/mid-pregnancy 25-hydroxyvitamin D (25(OH)D) and neonatal cord blood 25(OH)D concentrations are associated with Negative affectivity in infancy. We studied term-born infants from the vitamin D Intervention in Infants study (VIDI, $n=777$, follow-up rate $80 \%$, Finland), and the Generation R Study ( $n=1505$, follow-up rate $40 \%$, Netherlands). We measured maternal serum 25(OH)D at 6-27 weeks (VIDI) or 18-25 weeks (Generation R) of pregnancy, and cord blood 25(OH) $\mathrm{D}$ at birth (both cohorts). Caregivers rated infant Negative affectivity at 11.7 months (VIDI) or 6.5 months (Generation R) using the Revised Infant Behavior Questionnaire. Using linear regression, we tested associations between 25(OH)D and Negative affectivity adjusted for infant age, sex, season of 25(OH)D measurement, maternal age, education, smoking, and body-mass-index. Per $10 \mathrm{nmol} / \mathrm{l}$ increase in maternal early/mid-pregnancy 25(OH)D, infant Negative affectivity decreased by 0.02 standard deviations (95\% confidence interval $[\mathrm{CI}]-0.06,-0.004)$ in VIDI, and 0.03 standard deviations (95\% CI $-0.03,-0.01)$ in Generation R. Cord blood $25(\mathrm{OH}) \mathrm{D}$ was associated with Negative affectivity in Generation R $(-0.03$, $95 \% \mathrm{CI}-0.05,-0.01)$, but not VIDI $(0.00,95 \% \mathrm{CI}-0.02,0.02)$. Lower maternal $25(\mathrm{OH}) \mathrm{D}$ concentrations were consistently associated with higher infant Negative affectivity, while associations between cord blood $25(\mathrm{OH}) \mathrm{D}$ concentrations and Negative affectivity were less clear. Maternal vitamin D status during early- and mid-pregnancy may be linked with early-emerging differences in offspring behavior.
\end{abstract}

Keywords Vitamin D $\cdot$ Prenatal $\cdot$ Temperament $\cdot$ Negative affectivity $\cdot$ Infant mental health $\cdot$ Nutrition

Kati Heinonen

kati.heinonen-tuomaala@tuni.fi

1 Department of Child and Adolescent Psychiatry/Psychology, Erasmus MC, Sophia Children's Hospital, Rotterdam, The Netherlands

2 Department of Social and Behavioral Science, Harvard T.H. Chan School of Public Health, Boston, MA, USA

3 Pediatric Research Center, Children's Hospital, University of Helsinki and Helsinki University Hospital, Helsinki, Finland

4 Research Program for Clinical and Molecular Metabolism, Faculty of Medicine, University of Helsinki, Helsinki, Finland
5 Folkhälsan Research Center, Helsinki, Finland

6 National Institute for Health and Welfare (THL), Helsinki, Finland

7 PEDEGO Research Unit, MRC Oulu, Oulu University Hospital and University of Oulu, Oulu, Finland

8 Department of Psychology and Logopedics, Faculty of Medicine, University of Helsinki, Helsinki, Finland

9 Department of Psychology, Education and Child Studies, Erasmus School of Social and Behavioural Sciences, Erasmus University Rotterdam, Rotterdam, The Netherlands

10 Psychology/Welfare Sciences, Faculty of Social Sciences, Tampere University, 33014 Tampere, Finland 


\section{Introduction}

Vitamin D is an essential micronutrient and neurosteroid that can influence fetal brain development [1-3]. During gestation, the fetus cannot synthesize vitamin $\mathrm{D}$, but rather maternal vitamin D is transported across the placenta, which may also play an active role in the metabolism of this prohormone into its active form [1,3-5]. Since fetal vitamin D status depends on maternal supply, maternal vitamin $\mathrm{D}$ concentrations can be seen as the determinant or proxy of the closely correlated fetal vitamin D status [1, $3,4]$. Further, neonatal vitamin D concentrations measured from cord blood at birth can be used as a marker of fetal vitamin D status at the end of gestation $[1,4]$.

Vitamin D insufficiency is common and can have longlasting implications for the offspring. Worldwide, one in every two pregnant women are estimated to have vitamin D insufficiency (serum 25-hydroxyvitamin D $(25(\mathrm{OH})$ D) $<50 \mathrm{nmol} / \mathrm{L}$ ), however the cut-offs used to define deficient or optimal levels of $25(\mathrm{OH}) \mathrm{D}$ often vary between studies [1]. A recent meta-analysis found evidence for associations between maternal prenatal vitamin D status and child neurobehavioral outcomes to be mixed. [6] Some, but not all $[7,8]$ previous studies have reported that low maternal vitamin D concentrations during pregnancy are associated with an increased risk of mental health problems in the offspring, including behavioral problems and diagnosis of attention deficit/hyperactivity disorder (ADHD), autism spectrum disorder (ASD), and depression. [9-15] Lower cord blood 25(OH)D concentrations at birth have also been associated with poorer mental health outcomes [13, 16-18], however, these may be less predictive of child neurobehavioral outcomes, compared to early- and mid-pregnancy maternal measurements $[6,11]$.

However, it is unclear if maternal or cord blood vitamin D concentrations are associated with differences in child temperament. Temperament refers to early-emerging, individual differences in behavior that are relatively constant across time, and can predict mental health throughout the lifespan $[19,20]$. Thus, an association between 25(OH)D and temperament could also help understand later-emerging differences in mental health.

In the current study, we compared results from two independent well-characterized studies: the Vitamin D Intervention in Infants (VIDI) study from Finland, and the Generation R Study, a population-based pregnancy cohort from the Netherlands. Our objective was to assess if maternal $25(\mathrm{OH}) \mathrm{D}$ during early or mid-pregnancy and cord blood 25(OH)D at birth are associated with Negative affectivity. This temperament trait is particularly interesting for two main reasons. Firstly, unlike some of the lateremerging traits, Negative affectivity can be assessed early in infancy, during which it manifests as a tendency to cry and express fear and distress easily, and to recover from distress slowly [19, 20]. Secondly, individuals who display more Negative affectivity in infancy have been shown to have an increased risk of ADHD and ASD, and show more internalizing symptoms in childhood and adolescence [19].

\section{Methods}

\section{Participants}

VIDI originally comprised 975 infants born in Helsinki, Finland in 2013-2014, and has been previously described [21, 22]. Briefly, healthy, term-born, appropriate-for-gestationalage (AGA) infants were randomized to daily vitamin D3 supplementation of $10 \mu \mathrm{g}$ (standard-dose) or $30 \mu \mathrm{g}$ (highdose) from 2 weeks to 2 years of life (ClinicalTrials.com registration NCT01723852). Data collected before and at birth were observational, and infant supplementation was independent of maternal/cord blood $25(\mathrm{OH}) \mathrm{D}$ concentrations and background characteristics (please see Supporting information). Of the 975 infants, 777 (80\%) had data on maternal or cord blood $25(\mathrm{OH}) \mathrm{D}$, Negative affectivity, and covariates, and were included in the current study.

The Generation R Study is a multiethnic populationbased prospective cohort that has been previously described elsewhere [23]. Briefly, pregnant women living in Rotterdam, the Netherlands, with an expected delivery date in 2002-2006 were recruited. This cohort included 3759 term-born, AGA infants whose parents were born in the Netherlands. Of these 3759 infants, 1505 (40\%) had data on maternal or cord blood $25(\mathrm{OH}) \mathrm{D}$, Negative affectivity, and covariates, and were included in the current study.

For more details of study protocols and participant flow, please see Supporting Information.

\section{Maternal and cord blood vitamin D concentrations}

In VIDI, 25(OH)D concentrations were analyzed from maternal blood samples collected at 6-27 weeks of gestation (mean $=11.3, \mathrm{SD}=1.9)$, and from cord blood collected at birth at 37-42 weeks of gestation (mean $=40.2, \mathrm{SD}=1.1$ ). Maternal pregnancy serum 25(OH)D and cord blood plasma $25(\mathrm{OH}) \mathrm{D}$ concentrations were analyzed with a fully automated IDS-iSYS immunoassay system with chemiluminescence detection. Intra-assay variations were 7\% (pregnancy) and $13 \%$ (cord blood). Linear agreement with liquid chromatography in tandem with mass spectrometry was good $\left(R^{2}=0.942\right)$.

In Generation R, 25(OH)D concentrations were analyzed from maternal blood samples collected at 18-25 weeks of gestation $($ mean $=20.5, \mathrm{SD}=1.0)$ and from cord blood 
samples collected at birth at 37-42 weeks of gestation (mean $=40.2, \mathrm{SD}=1.2$ ) [25]. Samples were quantified using isotope dilution liquid chromatography-tandem mass spectrometry: the analytical system consisted of a Shimadzu Nexera UPLC coupled to an AbSciex 5500 QTRAP equipped with an APCI source, with inter-assay imprecision $<11 \%$.

$25(\mathrm{OH}) \mathrm{D}$ reflected sum of $25(\mathrm{OH}) \mathrm{D} 2$ and $25(\mathrm{OH}) \mathrm{D} 3$ concentrations. Please see Supporting Information for methodological details.

\section{Infant temperament: negative affectivity}

The Infant Behavior Questionnaire, Revised version (IBQ$\mathrm{R})$ was used in both studies [24]. IBQ-R yields 14 subscale scores, each of which contribute to one of the 3 broad-band scales. Only the Negative affectivity broadband scale was assessed in both studies.

Parents filled out the questionnaire at the mean child age of 11.7 ( $\mathrm{SD}=0.58$ months) months in VIDI and 6.5 $(\mathrm{SD}=0.9)$ months in Generation $\mathrm{R}$. The four subscale scores, Sadness (indicating lower general mood), Distress to Limitations (crying, fussing, expressing distress when faced with limitations), Fear (becoming distressed/startled when exposed to new situations/stimuli), and Recovery from distress (slower recovery from distress/arousal; inverse-coded so that higher scores on all scales reflect increased Negative affectivity) were standardized within the sample (mean $=0$, $\mathrm{SD}=1$ ). We calculated Negative affectivity scores as the average score across the four subscales: higher scores indicate more negative affectivity. The assessment is described in more detail in Supporting Information.

\section{Statistical analyses}

We conducted all analyses separately in VIDI and in Generation R. In the main analyses, we used separate multivariate linear regression models to examine associations between maternal $25(\mathrm{OH}) \mathrm{D}$ concentration during pregnancy or cord blood 25(OH)D concentration at birth, and Negative affectivity.

Child age and sex were included as covariates in the basic model. Potential maternal confounders were selected based on theoretical background, and included in the adjusted model. These were maternal age (years), self-reported education (upper tertiary/lower tertiary/lower), early-pregnancy BMI $\left(\mathrm{kg} / \mathrm{m}^{2}\right)$, smoking during pregnancy (yes/no), and season at the time of $25(\mathrm{OH}) \mathrm{D}$ measurement (December-February/March-May/June-August/September-November). In sensitivity analyses, we further adjusted for prenatal maternal (1) self-reported depressive symptoms, and (2) thyrotropin concentrations: both covariates were only available in Generation R. Please see Supporting Information for details on covariate selection and data.
We then ran secondary analyses. First, we tested associations between $25(\mathrm{OH}) \mathrm{D}$ concentrations and the four subscale scores: sadness, distress to limitations, fear, and rate of falling reactivity.

Second, we categorized $25(\mathrm{OH}) \mathrm{D}$ concentration into five groups: $<25 \mathrm{nmol} / 1,25-49.9 \mathrm{nmol} / 1,50-74.9 \mathrm{nmol} / \mathrm{l}$, $75-125 \mathrm{nmol} / \mathrm{l}$, and $>125 \mathrm{nmol} / \mathrm{l}$. To identify vitamin $\mathrm{D}$ insufficiency in the general population, a cut-off of $50 \mathrm{nmol} / \mathrm{l}$ is often recommended, however, lower cut-offs (such as $<25 \mathrm{nmol} / \mathrm{l}$ [25]) can be used to identify profound vitamin D deficiency [25-28]. Higher cut-offs (such as $<75 \mathrm{nmol} / 1$ [25]) have been recommended to identify levels that, despite being sufficient for bone health, may be non-optimal for perinatal, metabolic and other health outcomes $[25,29]$. Finally, some studies suggest that concentrations beyond $>125 \mathrm{nmol} / \mathrm{l}$ may be associated with harm, and the US Institute of Medicine for example has adopted this cut-off to select tolerable upper intake levels [27, 28]. Because there is no consensus over the optimal categorization of maternal or cord blood $25(\mathrm{OH}) \mathrm{D}$, we used these previously recommended cut-offs to categorize $25(\mathrm{OH}) \mathrm{D}$. In linear regression models, we used the group with $25(\mathrm{OH}) \mathrm{D}$ 75-125 nmol/l ("optimal") as the reference group, and compared participants with $25(\mathrm{OH}) \mathrm{D}$ deficiency $(<25 \mathrm{nmol} / \mathrm{l})$, insufficiency (25-49.9 nmol/l), suboptimal concentration $(50-74.9 \mathrm{nmol} / \mathrm{l})$, and high concentration $(>125 \mathrm{nmol} / \mathrm{l})$ against this reference group. In VIDI, only one participant had $25(\mathrm{OH}) \mathrm{D}<25 \mathrm{nmol} / \mathrm{l}$ during pregnancy and was excluded in the categorical analyses. None of the VIDI participants had 25(OH)D $<25 \mathrm{nmol} / \mathrm{l}$ at birth. In Generation $\mathrm{R}$, only two participants had $25(\mathrm{OH}) \mathrm{D}>125 \mathrm{nmol} / \mathrm{l}$ at birth, and were excluded in the categorical analyses.

Third, we examined potential U-shaped associations by adding a quadratic term of $25(\mathrm{OH}) \mathrm{D}$ in the main models. Some evidence suggests that both high and low neonatal $25(\mathrm{OH}) \mathrm{D}$ concentrations could be associated with poorer mental health outcomes [30].

Fourth, we examined moderation by sex by adding an interaction term (child sex $\times 25(\mathrm{OH}) \mathrm{D}$ concentration) into the main models. Some previous evidence suggests that associations between maternal $25(\mathrm{OH}) \mathrm{D}$ and child behavioral symptoms vary by sex [9].

Finally, in non-response analyses, we compared analytical sample against those who were not included in the study because of missing data, using independent $t$-tests, Mann-Whitney U tests, and chi-squared tests. In Generation $\mathrm{R}, 22 \%$ of otherwise eligible participants were lost due to missing covariate data (compared with only $5 \%$ in VIDI). In supplementary analyses, we added these otherwise eligible Generation $\mathrm{R}$ participants into the analytical sample, used MICE in R (30 datasets, 10 iterations) to impute missing covariate data, and re-ran the fully adjusted main analyses in Generation R [31]. 


\section{Results}

Table 1 presents the sample characteristics. On average, the 777 mothers in VIDI were 31.2 years old, $74 \%$ had BMI $18.5-24.9 \mathrm{~kg} / \mathrm{m}^{2}, 14.1 \%$ smoked during pregnancy, and $46.6 \%$ had upper tertiary education. Among the 1,505 mothers in Generation R, average age was 31.6 years, $66.9 \%$ had BMI $18.5-24.9 \mathrm{~kg} / \mathrm{m}^{2}, 21.9 \%$ smoked during pregnancy, and $45.1 \%$ had upper tertiary education. Figure 1 illustrates maternal 25(OH)D concentrations during pregnancy (Fig. 1a) and cord blood 25(OH)D concentrations at birth (Fig. 1b). We report results from the adjusted models in the text (for results from basic models, please see Supplementary Table 1).

Mothers in the VIDI analytical sample were less often smokers and had higher $25(\mathrm{OH}) \mathrm{D}$ in pregnancy, and their offspring had higher cord blood 25(OH)D at birth and were younger at follow-up, compared with those who could not be included in the analytical sample ( $n=198$, Supplementary Table 2). In Generation R, mothers in the analytical sample were older, more highly educated, less often depressed, less often smoked, and had higher 25(OH)D concentrations during pregnancy, and the infants in the analytical sample were younger, compared with those who could not be included ( $n=2254)$ (Supplementary Table 2$)$.

\section{Maternal 25(OH)D during pregnancy and infant temperament}

In both cohorts, higher maternal $25(\mathrm{OH}) \mathrm{D}$ concentration during pregnancy was associated with lower infant Negative affectivity, when controlling for child sex and age, and maternal age, education, BMI, smoking, and season of 25(OH)D measurement (Table 2). The effect estimates were similar across cohorts: for every $10 \mathrm{nmol} / \mathrm{l}$ increase in maternal $25(\mathrm{OH}) \mathrm{D}$, infants had $0.03 \mathrm{SD}$ units $(95 \%$ CI -0.06 to -0.004$)$ and 0.02 SD units $(95 \%$ CI -0.03 to -0.01$)$ lower Negative affectivity scores in VIDI and Generation R, respectively (Table 2). This association remained similar after additionally adjusting for maternal depressive symptoms $(-0.02 \mathrm{SD}, 95 \% \mathrm{CI}-0.03$ to -0.01$)$ or thyrotropin $(-0.03 \mathrm{SD}, 95 \% \mathrm{CI}-0.04,-0.01)$ (depression and thyrotropin data only available in Generation R). In subscale analyses, lower maternal 25(OH)D was associated with higher distress to limitations and slower recovery from distress in both cohorts, and with higher sadness in Generation R (Supplementary Table 3).

Table 3 shows associations between categorical maternal $25(\mathrm{OH}) \mathrm{D}$ in pregnancy and infant Negative affectivity. In both samples, the infants whose mothers had the lowest $25(\mathrm{OH}) \mathrm{D}$ during pregnancy had the highest Negative affectivity in infancy, but most differences between the groups were not statistically significant. Only Generation $\mathrm{R}$ had enough mothers with $25(\mathrm{OH}) \mathrm{D}<25 \mathrm{nmol} / \mathrm{l}$ during pregnancy to test if vitamin $\mathrm{D}$ deficiency, defined using this strict cut-off, was associated with infant temperament: compared with infants whose mothers had "optimal" 25(OH)D (75-125 nmol/l), the infants whose mothers had $25(\mathrm{OH}) \mathrm{D}<25 \mathrm{nmol} / \mathrm{l}$ had $0.25 \mathrm{SD}$ units higher Negative affectivity (95\% CI 0.08-0.42) (Table 3). Infants whose mothers had high $25(\mathrm{OH}) \mathrm{D}(>125 \mathrm{nmol} / \mathrm{l})$ did not differ from the reference group (75-125 nmol/l) (Table 3).

Inclusion of a quadratic term in the models did not suggest a U-shaped association between maternal $25(\mathrm{OH}) \mathrm{D}$ and infant Negative affectivity ( $p$ values $>0.09$ ).

\section{Cord blood 25(OH)D at birth and temperament in infancy}

In VIDI, we observed no association between cord blood $25(\mathrm{OH}) \mathrm{D}$ concentrations at birth and Negative affectivity (Table 2). In Generation R, however, higher 25(OH)D at birth was associated with lower infant Negative affectivity: per $10 \mathrm{nmol} / \mathrm{l}$ increase in cord blood 25(OH)D concentration at birth, negative affectivity scores were $0.03 \mathrm{SD}$ lower in infancy $(95 \% \mathrm{CI}-0.05,-0.01)$ (Table 2). This association remained similar when we additionally adjusted for maternal depressive symptoms $(-0.04,95 \% \mathrm{CI}-0.06,-0.01)$ or thyrotropin $(-0.03,95 \% \mathrm{CI}-0.06,-0.003)$. When examining subscale-level associations, higher cord blood 25(OH)D was associated with lower distress to limitations and faster recovery from distress (in Generation R) (Supplementary Table 3).

However, when we compared infants with cord blood $25(\mathrm{OH}) \mathrm{D}<25 \mathrm{nmol} / \mathrm{l}, 25-50 \mathrm{nmol} / \mathrm{l}, 50-75 \mathrm{nmol} / \mathrm{l}$, or $>125 \mathrm{nmol} / \mathrm{l}$, to the reference group $(75-125 \mathrm{nmol} / \mathrm{l})$, we found no differences in Negative affectivity in either cohort (Table 3). Table 3 also illustrates the lack of any clear pattern of effects (where the groups with the lowest cord blood $25(\mathrm{OH}) \mathrm{D}$ concentrations would have the highest Negative affectivity), in contrast to the pattern observed for maternal $25(\mathrm{OH}) \mathrm{D}$ during pregnancy.

Finally, we found no evidence of a U-shaped association between cord blood 25(OH)D at birth and Negative affectivity in either cohort (quadratic term $p$ values $>0.58$ ).

\section{Moderation by sex}

There was no evidence of an interaction between infant sex and maternal or cord blood $25(\mathrm{OH})$ D concentration in predicting infant Negative Affectivity in either cohort ( $p$ values $>0.21$ ). 
Table 1 Characteristics of the VIDI and Generation R Study participants

\begin{tabular}{|c|c|c|c|c|}
\hline \multirow[t]{3}{*}{ Characteristics } & \multicolumn{2}{|l|}{ VIDI } & \multicolumn{2}{|l|}{ Generation $\mathrm{R}$} \\
\hline & \multicolumn{2}{|l|}{ Total $N=777$} & \multicolumn{2}{|l|}{ Total $N=1505$} \\
\hline & Mean (SD) [range] or $n(\%)$ & $N$ & Mean (SD) [range] or $n(\%)$ & $N$ \\
\hline \multicolumn{5}{|l|}{ Maternal characteristics } \\
\hline Pregnancy $25(\mathrm{OH}) \mathrm{D}, \mathrm{nmol} / \mathrm{l}$ & $82.7(20.4)[24.8,189.2]$ & 651 & $69.3(28.2)[3.8,144.6]$ & 1398 \\
\hline$<25 \mathrm{nmol} / \mathrm{l}, n(\%)$ & $1(0.2)$ & & $67(4.8)$ & \\
\hline $25-49.9 \mathrm{nmol} / \mathrm{l}, n(\%)$ & $23(3.5)$ & & $319(22.8)$ & \\
\hline $50-74.9 \mathrm{nmol} / 1, n(\%)$ & $209(32.1)$ & & $418(27.8)$ & \\
\hline $75-125 \mathrm{nmol} / \mathrm{l}, n(\%)$ & $402(61.8)$ & & $558(37.1)$ & \\
\hline$>125 \mathrm{nmol} / \mathrm{l}, n(\%)$ & $16(2.5)$ & & $36(2.4)$ & \\
\hline Pregnancy $25(\mathrm{OH}) \mathrm{D}$ measurement season & & 651 & & 1398 \\
\hline Winter (Dec, Jan, Feb), $n(\%)$ & $144(22.1)$ & & $290(20.7)$ & \\
\hline Spring (Mar, Apr, May), $n(\%)$ & $97(14.9)$ & & $372(26.6)$ & \\
\hline Summer (Jun, Jul, Aug), $n(\%)$ & $168(25.8)$ & & $403(28.8)$ & \\
\hline Autumn (Sep, Oct, Nov), $n(\%)$ & $242(37.2)$ & & $333(23.8)$ & \\
\hline GA at $25(\mathrm{OH}) \mathrm{D}$ measurement, weeks & $11.3(1.9)[6.1,27.1]$ & 651 & $20.5(1.0)[18.1,24.8]$ & 1398 \\
\hline Age at enrolment, years & $31.2(4.3)[19.0,44.0]$ & 777 & $31.6(4.2)[16.8,46.3]$ & 1505 \\
\hline Early-pregnancy BMI, kg/m² & & 777 & & 1505 \\
\hline$<18.5, n(\%)$ & $21(2.7)$ & & $29(1.9)$ & \\
\hline $18.5-24.9, n(\%)$ & $575(74.0)$ & & $1007(66.9)$ & \\
\hline $25-29.9, n(\%)$ & $135(17.4)$ & & $339(22.5)$ & \\
\hline 30 or more, $n(\%)$ & $46(5.9)$ & & $130(8.6)$ & \\
\hline Smoking, $n(\%)$ & $109(14.1)$ & 777 & $330(21.9)$ & 1505 \\
\hline Educational level & & 777 & & 1505 \\
\hline Primary/secondary, $n(\%)$ & $189(24.3)$ & & $407(27.0)$ & \\
\hline Lower tertiary, $n(\%)$ & $226(29.1)$ & & $419(27.8)$ & \\
\hline Upper tertiary, $n(\%)$ & $362(46.6)$ & & $679(45.1)$ & \\
\hline BSI depression score during pregnancy & NA & & $0.11(0.32)[0,3.7]$ & 1374 \\
\hline BSI depression score $>0.8, n(\%)$ & NA & & $53(3.9)$ & \\
\hline Thyrotropin concentration, mU/l & NA & & $1.7(1.4)[0.0,25.4]$ & 1137 \\
\hline \multicolumn{5}{|l|}{ Infant characteristics } \\
\hline Cord blood 25(OH)D, nmol/l & $82.8(26.3)[36.7,283.7]$ & 763 & $40.6(20.5)[4.9,129.5]$ & 1053 \\
\hline$<25 \mathrm{nmol} / \mathrm{l}, n(\%)$ & $0(0)$ & & $265(25.2)$ & \\
\hline $25-49.9 \mathrm{nmol} / 1, n(\%)$ & $27(3.5)$ & & $466(44.3)$ & \\
\hline $50-74.9 \mathrm{nmol} / 1, n(\%)$ & $287(37.6)$ & & $259(24.6)$ & \\
\hline $75-125 \mathrm{nmol} / \mathrm{l}, n(\%)$ & $415(54.4)$ & & $61(5.8)$ & \\
\hline$>125 \mathrm{nmol} / \mathrm{l}, n(\%)$ & $34(4.5)$ & & $2(0.2)$ & \\
\hline Cord blood 25(OH)D measurement season & & 763 & & 1053 \\
\hline Winter (Dec, Jan, Feb), $n(\%)$ & $144(18.9)$ & & $298(28.3)$ & \\
\hline Spring (Mar, Apr, May), $n(\%)$ & $322(42.2)$ & & $267(25.4)$ & \\
\hline Summer (Jun, Jul, Aug), $n(\%)$ & $168(22.0)$ & & $275(26.1)$ & \\
\hline Autumn (Sep, Oct, Nov), $n(\%)$ & $129(16.9)$ & & $213(20.2)$ & \\
\hline Sex, female, $n(\%)$ & $498(51.2)$ & 777 & $751(49.9)$ & 1505 \\
\hline Age at IBQ-R assessment, months & $11.7(0.58)[8.9,16.1]$ & 777 & $6.5(0.9)[4.7,11.9]$ & 1505 \\
\hline
\end{tabular}

Data are means (SD) [range] unless stated otherwise. 25(OH)D concentration categorization was based on previously recommended cut-offs for $25(\mathrm{OH}) \mathrm{D}$ deficiency $(<25 \mathrm{nmol} / \mathrm{l})$, insufficiency $(<50 \mathrm{nmol} / \mathrm{l})$, suboptimal concentration $(<75 \mathrm{nmol} / \mathrm{l})$, and high concentration $(>125 \mathrm{nmol} / \mathrm{l})$ [25-27]

25(OH)D 25-hydroxyvitamin D, BSI Brief symptom inventory, BMI body-mass-index, GA gestational age, IBQ-R Infant Behavior Questionnaire, Revised, $N$ number of participants with available data, $n$ number of cases, $N A$ Data not available, $S D$ standard deviation, $\%$ proportion of cases among those with data available 

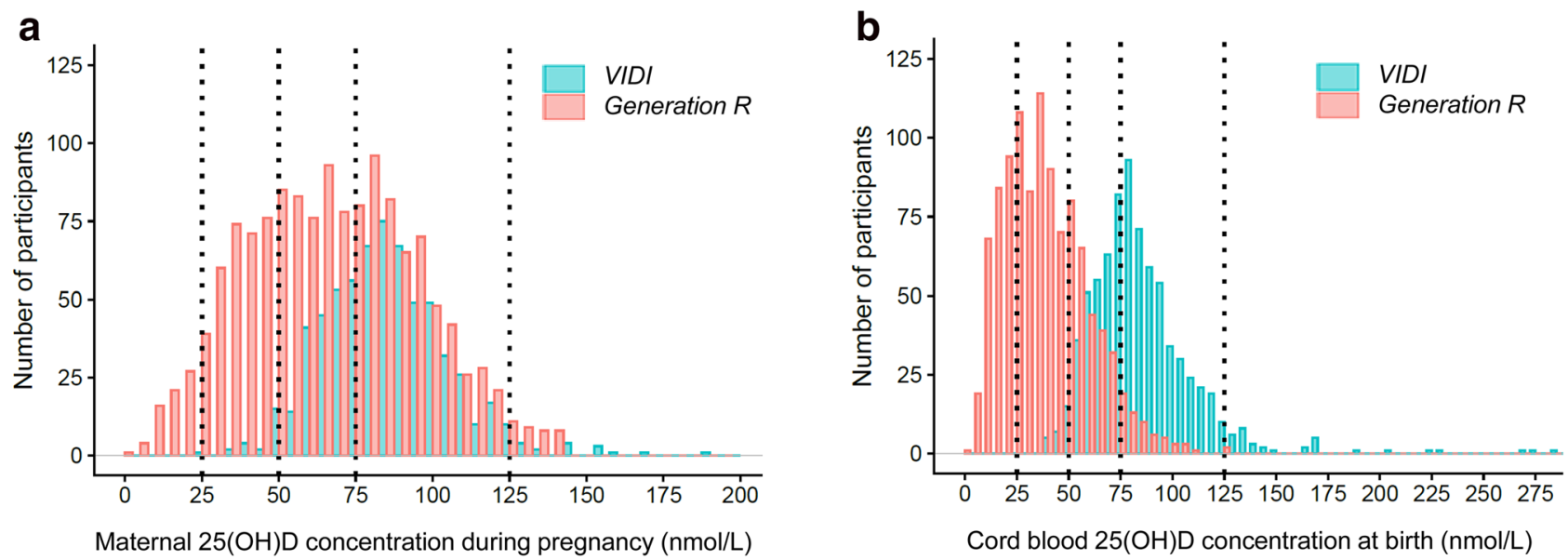

Fig. 1 The distribution of maternal 25(OHD) concentrations during pregnancy (a) and cord blood 25(OH)D concentrations at birth (b)

Table 2 Associations between $25(\mathrm{OH}) \mathrm{D}$ concentrations measured during pregnancy and at birth and infant negative affectivity in VIDI and in the Generation R Study

\begin{tabular}{lll}
\hline & EE $(95 \% \mathrm{CI})$ & $p$ \\
\hline Maternal 25(OH)D in pregnancy & & \\
VIDI & $-0.03(-0.06,-0.004)$ & 0.02 \\
Generation R Study & $-0.02(-0.03,-0.01)$ & 0.01 \\
Cord blood 25(OH)D at birth & & \\
VIDI & $0.00(-0.02,0.02)$ & 0.92 \\
Generation R Study & $-0.03(-0.05,-0.01)$ & 0.01 \\
\hline
\end{tabular}

Effect estimates are presented as change in Negative Affectivity, in SD units, per each $10 \mathrm{nmol} / \mathrm{l}$ increase in $25(\mathrm{OH}) \mathrm{D}$ concentration. Higher Negative affectivity reflects a tendency to cry and express fear and distress more easily and to recover from distress more slowly. We adjusted for child sex, age at assessment, maternal age, educational level, early-pregnancy BMI, smoking, and season of 25(OH)D measurement

25( $\mathrm{OH}) \mathrm{D}$ 25-hydroxyvitamin D, $E E$ non-standardized effect estimate from linear regression model, $C I$ confidence interval for effect estimate, $p p$ value

\section{Non-response analyses}

After imputing missing covariates in the otherwise eligible Generation R sample $(n=1930)$ (Supplementary Table 2$)$, associations between $25(\mathrm{OH}) \mathrm{D}$ in pregnancy and at birth and Negative affectivity remained very similar compared with the results from non-imputed data (per $10 \mathrm{nmol} / \mathrm{l}$ increase in maternal $25(\mathrm{OH}) \mathrm{D}$, Negative affectivity was $-0.02 \mathrm{SD}$ units lower $[p=0.001]$; per $10 \mathrm{nmol} / \mathrm{l}$ increase in cord blood $25(\mathrm{OH}) \mathrm{D}$, Negative affectivity was -0.03 $\mathrm{SD}$ units lower $[p=0.01])$.

\section{Discussion}

The present study demonstrated that higher maternal vitamin D concentration during pregnancy was associated with lower offspring Negative affectivity in infancy. Infants whose mothers had higher $25(\mathrm{OH}) \mathrm{D}$ concentration in early- and mid-pregnancy displayed lower distress to limitations and better recovery from distress at 6-12 months of age. This finding was similar across two independent samples of mother-child dyads from Finland and from the Netherlands.

We did not find evidence of a U-shaped association. Infants whose mothers had 25(OH)D concentrations above $125 \mathrm{nmol} / \mathrm{l} \mathrm{had} \mathrm{similar} \mathrm{levels} \mathrm{of} \mathrm{Negative} \mathrm{affectivity,} \mathrm{com-}$ pared with those who had concentrations between 75 and $125 \mathrm{nmol} / \mathrm{l}$. However, any adverse effects of extremely high $25(\mathrm{OH}) \mathrm{D}$ were beyond the scope of our study.

Somewhat surprisingly, vitamin D concentration at birth, measured from cord blood, was not consistently associated with infant Negative affectivity. In VIDI, we observed no association between cord blood 25(OH)D and Negative affectivity. In Generation R, lower cord blood 25(OH)D was associated with higher Negative affectivity when modelling $25(\mathrm{OH}) \mathrm{D}$ as a continuous variable. However, even within Generation R, the pattern of findings for categorized cord blood $25(\mathrm{OH}) \mathrm{D}$ was not as clear as the pattern observed for maternal $25(\mathrm{OH}) \mathrm{D}$ : infants with the lowest cord blood $25(\mathrm{OH}) \mathrm{D}$ concentrations did not have the highest Negative affectivity. We are not aware of any previous studies on cord blood 25(OH)D and temperament, and thus advise caution in interpreting these mixed results for cord blood. While it is possible that low $25(\mathrm{OH}) \mathrm{D}$ at birth is associated with higher Negative affectivity, the association in the current study was not as consistent as that between maternal early/ mid-pregnancy 25(OH)D and Negative affectivity. 
Table 3 Associations between 25(OH)D concentrations measured during pregnancy and at birth and categorized into five distinct categories, and infant negative affectivity

\begin{tabular}{|c|c|c|c|}
\hline & $N$ & $\mathrm{EE}(95 \% \mathrm{CI})$ & $p$ \\
\hline \multicolumn{4}{|c|}{ Maternal $25(\mathrm{OH}) \mathrm{D}$ in pregnancy } \\
\hline \multicolumn{4}{|l|}{ VIDI } \\
\hline$<25 \mathrm{nmol} / \mathrm{l}$ & 1 & $\mathrm{n} / \mathrm{a}$ & \\
\hline $25-49.9 \mathrm{nmol} / 1$ & 23 & $0.29(-0.01,0.59)$ & 0.06 \\
\hline $50-74.9 \mathrm{nmol} / 1$ & 209 & $0.11(-0.02,0.23)$ & 0.09 \\
\hline $75-125 \mathrm{nmol} / \mathrm{l}$ & 402 & Ref & \\
\hline$>125 \mathrm{nmol} / \mathrm{l}$ & 16 & $-0.05(-0.41,0.31)$ & 0.78 \\
\hline \multicolumn{4}{|l|}{ Generation R Study } \\
\hline$<25 \mathrm{nmol} / 1$ & 67 & $0.25(0.07,0.42)$ & 0.01 \\
\hline $25-49.9 \mathrm{nmol} / \mathrm{l}$ & 319 & $0.09(-0.01,0.19)$ & 0.06 \\
\hline $50-74.9 \mathrm{nmol} / 1$ & 418 & $-0.01(-0.10,0.08)$ & 0.82 \\
\hline $75-125 \mathrm{nmol} / \mathrm{l}$ & 558 & Ref & \\
\hline$>125 \mathrm{nmol} / \mathrm{l}$ & 36 & $-0.15(-0.38,0.08)$ & 0.21 \\
\hline \multicolumn{4}{|c|}{ Cord blood 25(OH)D at birth } \\
\hline \multicolumn{4}{|l|}{ VIDI } \\
\hline$<25 \mathrm{nmol} / \mathrm{l}$ & 0 & $\mathrm{n} / \mathrm{a}$ & \\
\hline $25-49.9 \mathrm{nmol} / \mathrm{l}$ & 27 & $0.01(-0.29,0.30)$ & 0.97 \\
\hline $50-74.9 \mathrm{nmol} / \mathrm{l}$ & 287 & $0.01(-0.10,0.12)$ & 0.87 \\
\hline $75-125 \mathrm{nmol} / 1$ & 415 & Ref & \\
\hline$>125 \mathrm{nmol} / \mathrm{l}$ & 34 & $-0.05(-0.31,0.21)$ & 0.72 \\
\hline \multicolumn{4}{|l|}{ Generation R Study } \\
\hline$<25 \mathrm{nmol} / 1$ & 265 & $0.04(-0.43,0.52)$ & 0.85 \\
\hline $25-49.9 \mathrm{nmol} / \mathrm{l}$ & 466 & $0.01(-0.36,0.37)$ & 0.98 \\
\hline $50-74.9 \mathrm{nmol} / \mathrm{l}$ & 259 & $0.12(-0.14,0.38)$ & 0.36 \\
\hline $75-125 \mathrm{nmol} / \mathrm{l}$ & 61 & Ref & \\
\hline$>125 \mathrm{nmol} / \mathrm{l}$ & 2 & $\mathrm{n} / \mathrm{a}$ & \\
\hline
\end{tabular}

Effect estimates are presented as change in Negative Affectivity, in SD units, from linear regression models where each of the groups was compared against the reference group with $25(\mathrm{OH}) \mathrm{D}$ concentration between 75 and $125 \mathrm{nmol} / \mathrm{l}$. Higher Negative affectivity reflects a tendency to cry and express fear and distress more easily and to recover from distress more slowly. We adjusted for child sex, age at assessment, maternal age, educational level, early-pregnancy BMI, smoking, and season of $25(\mathrm{OH}) \mathrm{D}$ measurement

25( $\mathrm{OH}) \mathrm{D}$ 25-hydroxyvitamin D, EE non-standardized effect estimate from linear regression model, $C I$ confidence interval for effect estimate, $n / a$ not applicable, this model could not be run because of the small number of cases, $p p$ value, ref reference group

Some indirect prior evidence supports the interpretation that early- and mid-pregnancy vitamin D concentrations could be important for fetal brain development, which in turn could help explain the temperamental differences observed in the current study. During this early period, fundamental structural development of the brain, including regions that are vital for behavioral regulation such as the prefrontal and limbic regions, occurs [32, 33]. In animal studies, vitamin D concentrations have been linked with multiple processes that take place during early fetal brain development, including neuronal migration and development of dendritic morphology and neuronal connectivity $[6,34]$. A recent meta-analysis suggested that early- to mid-gestation $25(\mathrm{OH}) \mathrm{D}$ concentrations could have a stronger effect on the neurodevelopment of the offspring, compared with $25(\mathrm{OH})$ D concentrations later in gestation [11].

The difference in Negative effectivity was approximately one-quarter of a standard deviation, between infants whose mothers had lowest $(<25 \mathrm{nmol} / \mathrm{l})$ vs "optimal" (75-125 nmol/l) 25(OH)D concentrations during pregnancy. Such small differences in an infant's tendency to express distress are not directly relevant for guiding clinical decisionmaking. However, identifying even subtle population-level effects can be meaningful, as understanding early environmental factors that influence behavioral phenotypes can elucidate the etiology of mental disorders, and help identify vulnerable populations and modifiable environmental risk factors. While we are not aware of previous studies on prenatal $25(\mathrm{OH}) \mathrm{D}$ concentrations and infant temperament, associations between prenatal vitamin $\mathrm{D}$ concentrations and psychopathology have been observed previously [9-14]. Negative affectivity, in turn, has been associated with psychopathology, including increased risk of ADHD, ASD, and internalizing in childhood and adolescence. [19] We encourage research into temperament as a potential mediating factor between maternal $25(\mathrm{OH}) \mathrm{D}$ during pregnancy and child psychopathology.

The current study has several strengths. First, a similar association between maternal 25(OH)D and infant Negative affectivity was shown in two independent samples, reducing the risk of chance findings and suggesting generalizability beyond just one country or population. Secondly, we used a standardized instrument, IBQ-R, to assess temperament in both samples. Thirdly, we addressed several potential sources of confounding by controlling for maternal age, education, smoking, BMI, depressive symptoms, thyrotropin, and season of 25(OH)D measurement. Further, to address potential confounding by ethnicity, we analyzed study samples that were ethnically homogenous. Finally, we measured $25(\mathrm{OH}) \mathrm{D}$ both in early/mid-pregnancy and at birth.

Some limitations need to be acknowledged. The low prevalence of low 25(OH)D $(<25 \mathrm{nmol} / \mathrm{l})$ in VIDI and of high $25(\mathrm{OH}) \mathrm{D}(>125 \mathrm{nmol} / \mathrm{l})$ in Generation R, especially at birth, limited the direct comparison of some results between the two cohorts, and could limit power to detect effects and e.g., cause underestimation of the effect magnitude. Two laboratories independently assessed $25(\mathrm{OH}) \mathrm{D}$ concentrations, and while differences in $25(\mathrm{OH}) \mathrm{D}$ status are likely to at least partly reflect true differences between populations $[35,36]$, we cannot rule out these were influenced by some methodological differences. Observed $25(\mathrm{OH}) \mathrm{D}$ concentrations may also not perfectly capture the bioavailable amount of vitamin $\mathrm{D}$, potentially introducing imprecision. 
Moreover, attrition can further limit generalizability to families with lower socioeconomic status. Further, any generalized conclusions based on these two studies in high-income European countries should be drawn with caution, as the effects could vary by population [6,37]. All infants in VIDI received standard or high-dose vitamin D supplementation, and Dutch guidelines also recommended vitamin D supplementation for infants, limiting the number of children exposed to both maternal and infant vitamin D insufficiency and any potentially additive effects [38]. Altogether, postnatal factors that could mediate or moderate associations between maternal and fetal vitamin D status and infant temperament were mostly beyond the scope of this study. While more research is needed to identify such factors, the fact that we observed these associations among AGA, termborn infants suggests that key perinatal complications such as preterm birth could not fully explain them. Finally, while several potential confounders were addressed, the risk of residual confounding inevitably remains (e.g., by genetic factors, maternal morbidities, and lifestyle factors explaining differences in nutritional status).

\section{Conclusion}

The current study showed an association between higher maternal vitamin D status during pregnancy and lower infant Negative affectivity. This supports the hypothesis that vitamin D plays a role in fetal neurodevelopment and is associated with early-emerging differences in child behavior.

Supplementary Information The online version contains supplementary material available at https://doi.org/10.1007/s00787-021-01894-4.

Author contributions $\mathrm{KH}$ and SS were responsible for planning and executing the analyses, interpreting the results, and writing the manuscript draft. EH-S, RZ, SV, JR, ME-C, HH, ML-P, HEM, HT, OM, SA, and KA all made substantial contributions to the design of the work or to data acquisition and interpretation, and revised the work critically for important intellectual content. All authors approved the submission of the current manuscript for publication and agree to be accountable for all aspects of the work in ensuring that questions related to the accuracy or integrity of any part of the work are appropriately investigated and resolved.

Funding The general design of the Generation R Study was supported by the Netherlands Organization for Scientific Research (NWO) and the Dutch Ministry of Health, Welfare, and Sport. The work of the authors involved in the Generation R Study in this project was supported by the LEaDing Fellows EU Marie Skłodowska-Curie COFUND Programme and the Orion Research Foundation (Dr Sammallahti); NWO Vici Grant 016.VICI.170.200 (Dr Tiemeier); and Stichting Volksbond Rotterdam, the Brain \& Behavior Research Foundation NARSAD Young Investigator Grant 27853, and the European Union's Horizon 2020 Research and Innovation Program LifeCycle grant No. 733206 (Dr El Marroun). The work of the authors involved in the VIDI study in this project was supported by the Academy of Finland (Dr Heinonen [grant n:o 345057]; Dr Outi Mäkitie, and Dr Lahti-Pulkkinen), by the
Sigrid Jusélius Foundation and the Novo Nordisk Foundation (Dr Outi Mäkitie), by the Päivikki and Sakari Sohlberg Foundation and the Juho Vainio Foundation (Dr Hauta-alus), by the Victoriastiftelsen, the Instrumentarium Science Foundation, the Paulo Foundation, and the Orion Research Foundation (Dr Enlund-Cerullo), and by Grants from Special Governmental Subsidy to Clinical Research, the Foundation for Pediatric Research in Finland, and Finska Läkaresällskapet (Dr Andersson). The funding sources had no role in study design, data collection and analysis, the interpretation or reporting of the results, or the decision to submit the manuscript for publication.

Availability of data and materials Requests to access VIDI and Generation R Study data can be sent to the corresponding author Kati Heinonen (kati.heinonen-tuomaala@tuni.fi) or to the Generation R Study data management (generationr@erasmusmc.nl), respectively. Requests to access individual-level data are subject to assessment and approval by the management teams of the studies, to ensure the privacy of the participants, which is protected by law.

Code availability Codes are available on request from the corresponding author Kati Heinonen (kati.heinonen@tuni.fi).

\section{Declarations}

Conflict of interest The authors have no relevant financial or non-financial interests to disclose.

Ethics approval The study was performed in accordance with the ethical standards as laid down in the Declaration of Helsinki. The VIDI study was approved by the Research Ethics Committee of the Hospital District of Helsinki and Uusimaa. The Generation R Study was approved by the Medical Ethical Committee of the Erasmus MC in Rotterdam.

Consent to participate Freely given written informed consent was obtained from all participating mothers.

Consent for publication Participants consented to have their data use in scientific research, including the publication of the study results in a way in which individual participants cannot be identified.

Open Access This article is licensed under a Creative Commons Attribution 4.0 International License, which permits use, sharing, adaptation, distribution and reproduction in any medium or format, as long as you give appropriate credit to the original author(s) and the source, provide a link to the Creative Commons licence, and indicate if changes were made. The images or other third party material in this article are included in the article's Creative Commons licence, unless indicated otherwise in a credit line to the material. If material is not included in the article's Creative Commons licence and your intended use is not permitted by statutory regulation or exceeds the permitted use, you will need to obtain permission directly from the copyright holder. To view a copy of this licence, visit http://creativecommons.org/licenses/by/4.0/.

\section{References}

1. Saraf R, Morton SMB, Camargo CA, Grant CC (2016) Global summary of maternal and newborn vitamin D status - a systematic review. Matern Child Nutr 12:647-668 
2. Cui X, Gooch H, Petty A et al (2017) Vitamin D and the brain: genomic and non-genomic actions. Mol Cell Endocrinol 453:131-143

3. Bendik I, Friedel A, Roos FF et al (2014) Vitamin D: a critical and essential micronutrient for human health. Front Physiol 5:248

4. Jacquemyn Y, Ajaji M, Karepouan N (2013) Vitamin D levels in maternal serum and umbilical cord blood in a multi-ethnic population in Antwerp, Belgium. Facts, Views Vis ObGyn 5:3-5

5. Liu NQ, Hewison M (2012) Vitamin D, the placenta and pregnancy. Arch Biochem Biophys 523:37-47

6. Mutua AM, Mogire RM, Elliott AM et al (2020) Effects of vitamin D deficiency on neurobehavioural outcomes in children: a systematic review. Wellcome Open Res 5:28

7. Gale CR, Robinson SM, Harvey NC et al (2008) Maternal vitamin D status during pregnancy and child outcomes. Eur J Clin Nutr 62:68-77

8. Keim S, Bodnar LM, Klebanoff MA (2014) Maternal and cord blood 25(OH)-vitamin D concentrations in relation to child development and behaviour. Paediatr Perinat Epidemiol 25:434-444

9. Daraki V, Roumeliotaki T, Koutra K et al (2018) High maternal vitamin $\mathrm{D}$ levels in early pregnancy may protect against behavioral difficulties at preschool age: the Rhea mother-child cohort, Crete, Greece. Eur Child Adolesc Psychiatry 27:79-88

10. Morales E, Julvez J, Torrent M et al (2015) Vitamin D in pregnancy and attention deficit hyperactivity disorder-like symptoms in childhood. Epidemiology 26:458-563

11. García-Serna AM, Morales E (2020) Neurodevelopmental effects of prenatal vitamin D in humans: systematic review and metaanalysis. Mol Psychiatry 25:2468-2481

12. Sucksdorff M, Brown AS, Chudal R et al (2021) Maternal vitamin $\mathrm{D}$ levels and the risk of offspring attention-deficit/hyperactivity disorder. J Am Acad Child Adolesc Psychiatry 60:142-151.e2

13. Lee BK, Eyles DW, Magnusson C et al (2021) Developmental vitamin $\mathrm{D}$ and autism spectrum disorders: findings from the Stockholm Youth Cohort. Mol Psychiatry 26:1578-1588

14. Strøm M, Halldorsson TI, Hansen S et al (2014) Vitamin D measured in maternal serum and offspring neurodevelopmental outcomes: a prospective study with long-term follow-up. Ann Nutr Metab 64:254-261

15. Francis EC, Charron E, Li M et al (2021) Third trimester maternal vitamin $\mathrm{D}$ and early childhood socioemotional development. Paediatr Perinat Epidemiol 35:350-358

16. Eyles DW, Trzaskowski M, Vinkhuyzen AAE et al (2018) The association between neonatal vitamin D status and risk of schizophrenia. Sci Rep 8:17692

17. Mossin $\mathrm{MH}$, Aaby JB, Dalgård $\mathrm{C}$ et al (2017) Inverse associations between cord Vitamin $\mathrm{D}$ and attention deficit hyperactivity disorder symptoms: a child cohort study. Aust N Z J Psychiatry 51:703-710

18. Schmidt RJ, Niu Q, Eyles DW et al (2019) Neonatal vitamin D status in relation to autism spectrum disorder and developmental delay in the CHARGE case-control study. Autism Res 12:976-988

19. Kostyrka-Allchorne K, Wass SV, Sonuga-Barke EJS (2020) Research review: do parent ratings of infant negative emotionality and self-regulation predict psychopathology in childhood and adolescence? A systematic review and meta-analysis of prospective longitudinal studies. J Child Psychol Psychiatry Allied Discip 61:401-416
20. Rothbart MK, Ahadi SA, Evans DE (2000) Temperament and personality: origins and outcomes. J Pers Soc Psychol 78:122-135

21. Rosendahl J, Valkama S, Holmlund-Suila E et al (2018) Effect of higher vs standard dosage of vitamin D3 supplementation on bone strength and infection in healthy infants. JAMA Pediatr 172:646

22. Helve O, Viljakainen H, Holmlund-Suila E et al (2017) Towards evidence-based vitamin D supplementation in infants: vitamin D intervention in infants (VIDI) - study design and methods of a randomised controlled double-blinded intervention study. BMC Pediatr 17:91

23. Jaddoe VWV, Mackenbach JP, Moll HA et al (2006) The Generation R Study: design and cohort profile. Eur J Epidemiol 21:475-484

24. Gartstein MA, Rothbart MK (2003) Studying infant temperament via the Revised Infant Behavior Questionnaire. Infant Behav Dev 26:64-86

25. Pearce SHS, Cheetham TD (2010) Diagnosis and management of vitamin D deficiency. BMJ 340:142-147

26. Munns CF, Shaw N, Kiely M et al (2016) Global consensus recommendations on prevention and management of nutritional rickets. Horm Res Paediatr 85:83-106

27. Ross AC, Manson JAE, Abrams SA et al (2011) The 2011 report on dietary reference intakes for calcium and vitamin $\mathrm{D}$ from the Institute of Medicine: what clinicians need to know. J Clin Endocrinol Metab 96:53-58

28. Institute of Medicine (2011) Dietary reference intakes for calcium and vitamin D. The National Academic Press, Washington

29. Aghajafari F, Nagulesapillai T, Ronksley PE et al (2013) Association between maternal serum 25-hydroxyvitamin D level and pregnancy and neonatal outcomes: systematic review and metaanalysis of observational Studies. BMJ 346:f1169

30. McGrath J, Eyles DW, Pedersen CB et al (2010) Neonatal vitamin D status and risk of schizophrenia. Arch Gen Psychiatry 67:889-894

31. van Buuren S, Groothuis-Oudshoorn K (2011) Mice: multivariate imputation by chained equations in R. J Stat Softw 45:1-67

32. Rice D, Barone S (2000) Critical periods of vulnerability for the developing nervous system: Evidence from humans and animal models. Environ Health Perspect 108:511-533

33. Keunen K, Counsell SJ, Benders MJNL (2017) The emergence of functional architecture during early brain development. Neuroimage 160:2-14

34. Janbek J, Specht IO, Heitmann BL (2019) Associations between vitamin D status in pregnancy and offspring neurodevelopment: a systematic literature review. Nutr Rev 77:330-349

35. Weggemans R, Schaafsma G, Kromhout D (2009) Naar een toereikende inname van vitamine D. Huisarts Wet 52:73-75 (Article in Dutch)

36. Itkonen ST, Andersen R, Björk AK et al (2020) Vitamin D status and current policies to achieve adequate vitamin $\mathrm{D}$ intake in the Nordic countries. Scand J Public Health 1-12

37. Chawla D, Fuemmeler B, Benjamin-Neelon SE et al (2019) Early prenatal vitamin D concentrations and social-emotional development in infants. J Matern Neonatal Med 32:1441-1448

38. Health Council of the Netherlands (2000) Dietary reference intakes: Calcium, vitamin D, thiamin, riboflavin, niacin, pantothenic acid, and biotin. Health Council of the Netherlands, The Hague 